[Please note, this is the author's version of work that has been accepted for publication in Computers and Education: currently in press]

\title{
The role of iPads in pre-school children's mark making development
}

\author{
Sara Price $^{\mathrm{a}}$, Carey Jewitt ${ }^{\mathrm{a}} \&$ Lucrezia Crescenzi Lanna $^{\mathrm{b}}$ \\ ${ }^{a}$ UCL Institute of Education, London \\ ${ }^{\mathrm{b}}$ Universitat de Vic, Barcelona
}

\begin{abstract}
The increased acquisition of touch-screen technologies, such as tablet computers, in both homes and schools raises important questions about their role for very young children's learning and development. Their inherent touch-based interaction offers new opportunities for mark making practices, which are linked to literacy development, through the emergent process of using marks as symbolic representation. This paper reports a comparative study of touch-based interaction using a tablet computer versus traditional physical paint and paper. Children aged 2-3 years engaged in a free finger painting activity and colouring in activity in both paper and digital environments. Video data of their interactions was used to develop a coding scheme for analyzing touch-based interaction, providing insight into how the use of fingers and hands differed in each environment, the different types and qualities of touch that were engendered, and the composition of the final paintings produced. Findings show that while the tablet computer limited the number of fingers used for interaction, its material affordances supported speed and continuity, which led to more mark making, and different 'scales' of mark making extending the range of mark making practices. At the same time it limited the sensory experience of physical paint and resulted in more uniform final compositions. The findings are discussed in terms of shaping young children's mark making, the implications of the use of touch screen technologies in literacy development for educational practitioners and technology design, and key future research directions.
\end{abstract}

\section{Keywords}

Touch, iPads, tablets, mark making, finger painting, pre-school, children.

\section{Introduction}

Everyday observations of pre-school children's use of mobile devices are increasingly being reported in the news, on blogs and web-based discussion boards. In general, these articles emphasise the ease with which very young children master touch-based interaction (e.g. LMC Academy, 2013). A recent review of the role of iPads for learning corroborates this, claiming them to be "easy to use, have a positive impact on student engagement, increasing motivation, enthusiasm, interest, independence and self-regulation, creativity and improved productivity" (Clarke \& Luckin, 2013, p.4; Pegrum, Oakley \& Faulkner, 2013). With the increase in touch devices in homes and schools debates around the value of these technologies for play and learning have arisen. These debates are typically driven by attitudes (both positive and negative) towards technology, which strongly effect educator's technology use (Blackwell, Lauricella \& Wartella, 2014), and make assumptions that can raise concerns about the extent of young children's use of digital technologies. This is especially true of touch screen devices, like iPads, which have become integral devices in people's homes (Flewitt, 2011; McPake, Plowman \& Stephen, 2013), and are interactively accessible to even very young infants. However, the assumptions underlying these views are not well grounded, highlighting the need to better understand the role of touchscreen technologies in pre-school contexts, and their implications for play and learning. This paper begins this process by examining touch-based interaction with pre-school children in both 
paper and digital contexts in order to identify how technology reshapes interaction. Specifically it examines differential roles of the paper and digital tools in mark making activity, and in so doing understand better their place in literacy skill development, and inform when and in what ways these technologies are useful in educational practice. It extends earlier work that used a multimodal analysis to explore concepts of touch as a 'mode' and the degree to which touch screens engender different kinds of touch movements (Author), but did not examine the implications of the study for pre-school mark making practices.

Drawing or mark making has long been acknowledged for its role in the development of fine motor skills, and as an important foundation for writing skill development (e.g. Coates \& Coates, 2006; Goodnow, 1977), being one example of unconventional writing practice that contributes to emergent literacy development (e.g. Sulzby and Teale, 1991). Children's early mark making evolves in a world that is imbued with signs and symbols - from written print, to logos, to pictures - experience of which is considered essential for fostering the development of literacy skills that include listening, reading, writing, and speaking (Strikland, 1990). Mark making, therefore, also contributes to the process of developing symbolic understanding and symbolic expression (Vygostsky, 1978), where children progress from making scribble like marks, to pictures, to the symbolic representation of ideas (Moyles, 1989). These drawings or scribble like marks are considered to be a form of proto-writing, with the 'meaning' initially only available to the child (Whitehurst and Lonigan, 1998), but as their symbolic understanding progresses become more recognizable to others. Understanding the symbolic potential of 'marks' enables children to use them as a means of conveying their thinking to others, thus serving as a tool for social communication (Ring, 2010), and as tools for expression in writing as well as mathematically (Caruthers and Worthington, 1988). In the context of recent reports highlighting the need for improving reading and writing skills, especially for boys (National Literacy Trust, 2008), who are also more reluctant to engage in drawing than girls (Anning \& Ring, 2004), coupled with an increasing need for developing digital literacy skills, this paper makes a contribution to understanding the role of touch-screen technologies in mark making practices.

Experiencing a range of activities is considered important for fostering mark making, for example various physical objects and materials, such as playdoh, sand, paint and pencils and crayons (Kress, 1997; Pahl, 1999). These early stages of mark making take place through hands on, or touch forms of, interaction. Touch interaction has specific sensory functions, providing ways of experiencing texture, shape and weight, as well as contributing to classification skills (Berk, 2012). In the form of finger painting or drawing touch has also been linked to the learning of traditional writing skills (e.g. Kress, 1997). Contemporary digital touch screens offer new tools for mark making, and for very young children this form of interaction with technology is more intuitive than computers that rely on mouse and keyboard, since it exploits their natural sensorimotor forms of interaction. However, little work to date has looked at the nature of the physical interface and its role in mark making practices, but rather has focused on its value in supporting the development of writing skills with older children using traditional desktop mousebased interaction (Arrowood \& Overall, 2004; Guthrie \& Richardson, 1995). In early years, studies of mark making with children aged 3-6 years found that stylus based tablets led to higher levels of engagement and final drawings above expectation for age (Couse \& Chen, 2010), and were superior to mouse-driven interaction for drawing (Matthews \& Seow, 2007). More recent work has shown that children of 4-5 years can use iPads in different ways to support emergent skills including drawing (Beschorner \& Hutchison, 2013), but has not examined the role of specific forms of touch-based interaction in early mark making activity. While Hillman and Marshall (2009) highlight important types of digital content to consider for supporting emergent literacy, this present research examines interactional modes, specifically touch-screen interaction with tablet computers. 
Previous research in children's mark making has shown visual feedback in response to children's mark making to be instrumental in fostering drawing development: the stronger the visual effect generated, the higher the quantity and quality of pre-drawing behavior (Dunst \& Gorman, 2009a). These findings are based on studies, which employed writing instruments, such as crayon, pen, stylus etc., but did not look at the use of finger digits for drawing. Research on finger drawing and haptic exploration in infants aged 7-21 months (Dunst \& Gorman, 2009b) has shown that the "likelihood of a child engaging in any type of finger drawing is maximized when the drawing act results in a discernable visual effect that functions as a reinforcement" (p. 3), and that modeling mother's behavior (finger drawing) coupled with multiple opportunities led to engaged interaction with computer screens.

Touch screen technologies offer several touch functions that include swiping, drag and drop, link clicking, as well as mark making. Research with younger children has shown their difficulty with mastering drag and drop gestures, suggesting that pointing type gestures are more effective and successful (Inkpen, 2000; Indriasari Mansor, De Angelis \& De Brujin, 2008; Joiner, Messer, Light, \& Littleton, 2008). For example, Indriasari Mansor et al., (2008) compared children's (aged 3-4 years) play with a real versus a virtual wooden tree house using a DiamondTouch interface. Analysis of children's competence and motor skill showed the atypical use of thumb or two fingers, instead of the index finger to touch the screen, and highlighted the problematic nature of being able to drag objects. Swipe actions have also been found to be problematic, as children tend to lift their touch during the action and fail to achieve the intended action on screen (Brown, Bonsignore, Hatley, Druin, Walsh, Foss et al., 2010). However, these studies mostly involve children of primary age and upwards, and aim to inform touch-based interface design (Anthony, Brown, Nias, Tate \& Mohan, 2012), with few studies focusing on pre-school children's interaction.

While this research provides a valuable foundation, little work to date has looked at how young children develop skills for technology-mediated touch-based interaction, and none at the role of touch-based digital interaction in early literacy development. With children increasingly being exposed to tablet forms of touch screen technologies from as young as a few months of age, coupled with the potential of touch-screens to support mark making activities, it is important to understand the role of this sensory form of interaction in children's skill development, to inform how it can be usefully used in pre-school educational contexts (both home and nursery). Thus a comparative study of finger painting in a digital and physical context was undertaken with preschool children, to examine differences in touch forms of interaction in the two mark making environments together with the composition of final paintings to gain insight into how touchscreen technologies might support or hinder mark making practices.

\section{Research Design and methods}

Access to nurseries willing to support technology mediated research was found to be problematic, since many were of the opinion that parents would prefer their children not to be using technology while at nursery, and impacted on the number of consenting participants. This study took place in the classroom of a London based pre-school nursery, which took children from infants to 4 years of age, and comprised different rooms and play areas appropriate for the various developmental stages of the children.

\subsection{Study design}

A quasi-experimental design was adopted in order to examine differences in touch interaction in the different mark making environments. A total of eleven children took part in the study and were selected on the basis of obtaining informed parental consent: 4 children took part in a pilot study to finalize the design (including informing which apps were most appropriate to use) and data collection methods prior to the main study; and 7 children ( 2 boys and 5 girls) in the main study. Participants were aged between 27 and 37 months, when children are typically in their first 
stages of drawing. A parental questionnaire showed that children in this study had little familiarity with iPad or tablet technology.

For the purposes of this study, iPads, as exemplary forms of tablet, were used along with physical paper and paint, to provide two environments for touch interaction activities, that enable mark making activity. Two existing iPad applications were selected on the basis that they enabled finger drawing on a blank screen; could show a few colors on the same window; and offered multi-touch capabilities with a simple graphic design (i.e. with only a small number of visible screen elements appropriate for this age group). These comprised the Doodle Buddy App: a blank screen with a paint palette (akin to a plain sheet of paper plus paint palette); and The Coloring Zoo: Finger painting using a 2D picture of a cat. For the paper condition a plain sheet of white paper and a white sheet of paper with an outline picture of the cat used in the digital version, together with a paint palette containing 5 paint colors were used. The physical dimension of the paint-pallet available in the nursery did not comfortably fit more than 5 colours, but appropriate digital paint applications all had more colours in the palette. The five physical paint colours were randomly chosen from the 9 available on the iPad condition.

Two researchers collected data during the school schedule over a five day period. Since familiarization with such young participants is critical, the researchers spent two days in the nursery with the participants before starting data collection. One researcher took responsibility for setting up each activity and monitoring the video recording; the other sat with each child as they engaged with the tasks to ensure that each child was comfortable/happy in their task. This included outlining the activity (would you like to draw a picture with the paint/iPad; and would you like to colour in the cat?), responding to interaction initiated by the children, and assessing when each child was ready to finish each task (e.g. when the child offered up a painting, or left the table). Each child freely explored both applications on the iPad, did a finger painting activity on a blank sheet of paper and the sheet with a pre-drawn image. Only one child at a time did the activities, and when others came over to join in the nursery staff encouraged them to engage in other activities in order to ensure that interaction was on an individual basis. A reverse order design was used to reduce the effect of order of activity on iPad or physical paper, where three children were randomly selected to begin with iPad activities and 4 to begin with the paper activities. Four children completed the cat drawing followed by the blank page/screen, and three did it in the reverse order: again randomly selected. Each session lasted an average of 5 minutes. Each activity finished when the child spent 10 seconds without touching the screen or the paper sheet.

Data collection primarily consisted of video data. Since video data offers its own complexities and limitations, video data was collected from various perspectives: screen capture on the iPad to record changes made on the screen; external video recording of the iPad screen and paper activities to record the movement of children's hands their touch interaction, and their sequence of actions and interactions with the iPad and physical devices; and micro cameras embedded in the frame of the iPad screen to record facial expression. These various perspectives were used to support triangulation of observation of interaction since each video perspective provides a particular component of data. The screen capture data provides access to the mark making in real time, while the external camera recording hand movements provides access to aspects relating to pressure of touch, facial expression, and activities between the touches on screen. Children did not demonstrate significant awareness of the external video camera (e.g. they did not look or wave at it). The paintings in both iPad and paper conditions were also collected to examine the final composition in conjunction with the ongoing composition observed during video analysis. Collectively this data provided access to the types of touch used, the associated marks made on the screen and paper, and the progressive composition of the paintings. 


\subsection{Data Analysis}

The data analysis aimed to identify the different ways that children make marks through touch, and thus focused on the kinds of touch that they used in the two environments, a measure of their usage, and their painting compositions, in order to consider whether the iPad engendered different touch movements - in quality or quantity and the impact of this on children's mark making. The analysis involved three researchers engaged in repeated video data viewing to develop a coding scheme (Author). The coding scheme was developed following an inductive method. After observing one video independently, the researchers agreed a coding scheme and developed a code-book (describing each code and exemplifying each option). The types of touch (e.g. "tap" or "scratch") and their quality (e.g. "small size: 2-4 cm"), included in the coding scheme were clearly defined. Rare occurrences of uncertainty that emerged during observation were discussed with other researchers in a meeting following the encoding of the data. Four dimensions of touch were identified: (i) Use of hands/fingers: whole hand(s), different fingers, and number of fingers; (ii) type of touch used (press, tap, straight stroke, circular stroke and scratch); (iii) character and quality of touch (direction of movement, 'scale/size' of mark, speed of touch, duration of touch, pressure); (iv) sequencing and configuration of touches. These aspects of touch interaction were considered important in shaping the mark making process. Key descriptions are condensed and reproduced as a table below for clarity (Table 1).

\begin{tabular}{|l|l|l|}
\hline \multirow{5}{*}{ Types of touch } & Tap & A short touch of the surface \\
\cline { 2 - 3 } & Press & A firm push on the surface, a longer tap \\
\cline { 2 - 3 } Straight stroke & $\begin{array}{l}\text { Finger held on surface and moved across to } \\
\text { make a line mark }\end{array}$ \\
\cline { 2 - 3 } Quality of touch & Circular stroke & $\begin{array}{l}\text { Finger held on surface and moved in a } \\
\text { circular fashion }\end{array}$ \\
\cline { 2 - 3 } & Scratch & $\begin{array}{l}\text { Use of nail or tip of finger to make a } \\
\text { scratching movement }\end{array}$ \\
\hline & Scale $/$ size & $\begin{array}{l}\text { Top to bottom/bottom to top/ left to } \\
\text { right/right to left/ }\end{array}$ \\
\cline { 2 - 3 } & Speed & $\begin{array}{l}\text { Tiny (tip finger) } / \text { small (2-4 cm)/ large over } 4 \\
\text { cm }\end{array}$ \\
\cline { 2 - 3 } & Duration & Slow or Fast \\
\cline { 2 - 3 } & Pressure & Short, Long \\
\hline
\end{tabular}

Table 1: Coding description

FinalCut Pro was used for organising the data, and enabling synchronization of the videos (Arend et al, 2014). All video data was coded using the qualitative analysis software, InqScribe - a video transcription tool, that enables each finger use, touch type and quality to be recorded and time stamped (Figure 1). 


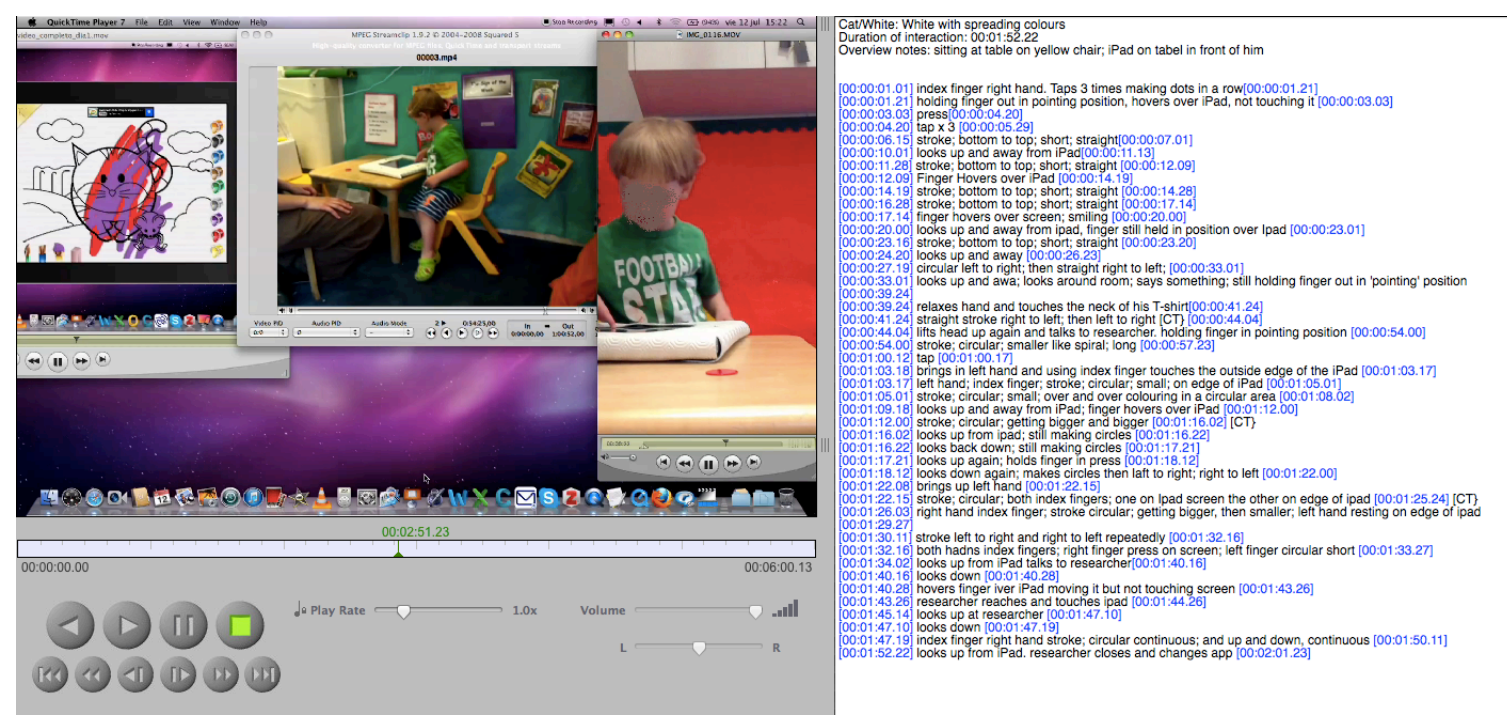

Figure 1: Screen shot using InqScribe transcription tool

\section{Results}

This section extends initial analysis (Author) to include results not previously reported, namely the total amount of touches and time spent in each environment; the different use of hands and digits; the quality of touch across the different environments; and the resulting paintings produced. While the distribution of different types of touch, and repeated and continued touch are also included, these results are used to bring a new analytical focus that examines their potential for mark making practices and informs educational practitioners.

\subsection{Overall touch interactions}

Overall the iPad environment involved more episodes of touch than the paint-paper. Children touched the iPad a total of 1048 times ( 985 on the screen, 63 on the 'palette'), compared with 933 touches with the paint-paper (719 on the paper, 214 on the paint-palette). Yet children spent the same average time interacting with the different environments (collective total time being 24.14 minutes on the iPad and 24.33 minutes on the paper). Looking at the different activities, fingerpainting with the cat drawing took an average of 2:04 minutes on paper, compared to 1:31 minutes on the iPad; free finger-painting on white paper took 1:41 minutes on paper, compared to 54 seconds on the iPad. The movement between paint palette and paper may account for this to some degree, since this distinctive repetitive rhythm and movement of their touch interaction differed markedly from the screen environment.

\subsection{Use of Hands and Fingers for Touching}

The digital and paper environments provided different possibilities for children's use of hands and fingers for touch-based interaction. Children used their palm when painting, and significantly more often with the paper sheet (28 times) than the iPad screen ( 3 times). The index finger was the most common finger used in both the paper and iPad environment, although there were differences in how they used this finger in the two environments. Several children held their index finger in a stiff pointing position throughout interaction with the iPad, even during pauses, when looking away, as if the finger was functioning as a 'tool' similar to a dedicated writing instrument. Overall children's use of thumb and range of fingers were more restricted with the iPad than the paper. 


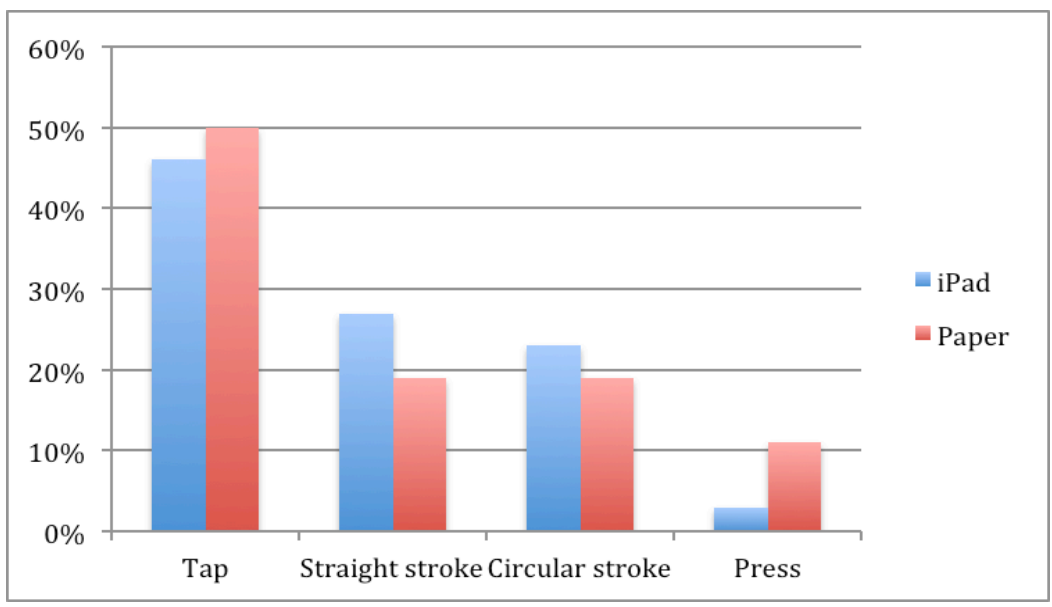

Figure 2: The distribution of touch types across environments

\subsection{Distribution of Types of Touch}

The results in this section (3.3) present a breakdown of touch within the site of interaction. (This draws on data reported elsewhere (Author) where the mode of touch and types of touch are in focus). As Figure 2 shows, the tap was the most common form of touch, and was used frequently in both environments. The straight stroke and circular stroke featured similarly in both environments, but slightly more in the iPad environment. The pressing touch featured significantly more in the paper than the iPad environment. A comparison of each environment overall suggests that the primary difference in amount of touch type is found in the press touch.

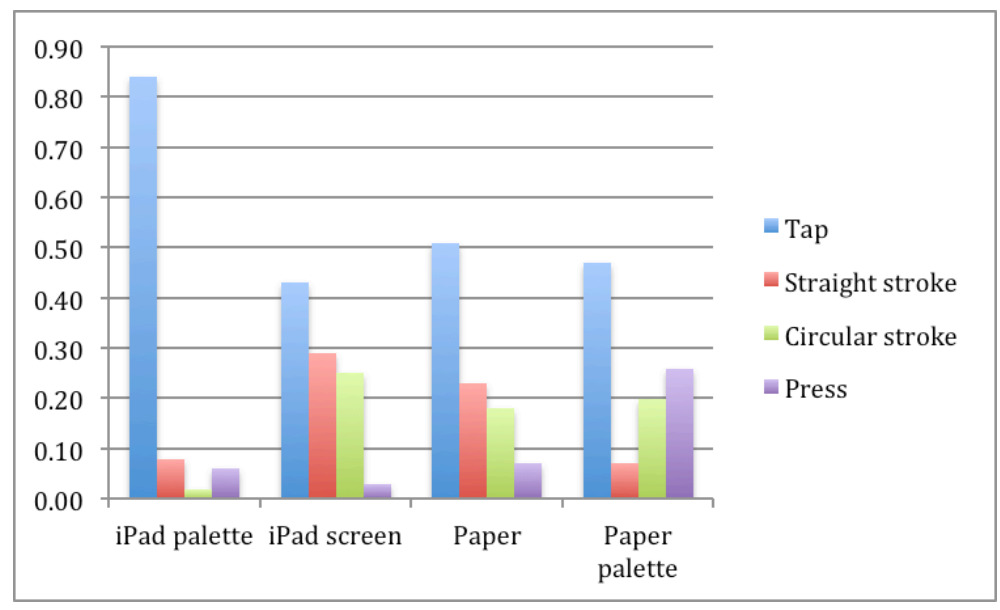

Figure 3: Breakdown of touches in each site of interaction

However, a breakdown within those environments shows the specific differences in touch in each site of interaction. Figure 3 shows the primary form of touch in the iPad palette was a tap with minimal evidence of other forms of touch. The iPad screen engendered a tap touch most frequently followed by similar amounts of straight and circular strokes, and a minimal number of presses. The paper similarly engendered a tap touch most frequently, but less of both straight and circular strokes. Touches in paper palette were made up of a mostly taps, a minimal number of straight strokes, but an equal number of circular strokes to the paper, and significantly more presses than in any other site of interaction.

\subsection{Repeated and Continuous Touch Sequences}

Repeated forms of touch and sequences of continuous touch were observed in both environments. Here Figure 4 shows that these forms of touch were significantly more prominent 
in the iPad than the paper environment and are reported here for their relevance in thinking about the role of touch screen interaction for pre-drawing skill development. Continuous sequences of touch were longer with the iPad than the paper: the maximum length of one continuous sequence in the iPad was 27 seconds, compared to 18 seconds with the paper. The total amount of time continuous touch was observed was 6:20 minutes with the iPad compared to 4:24 minutes with the paper.

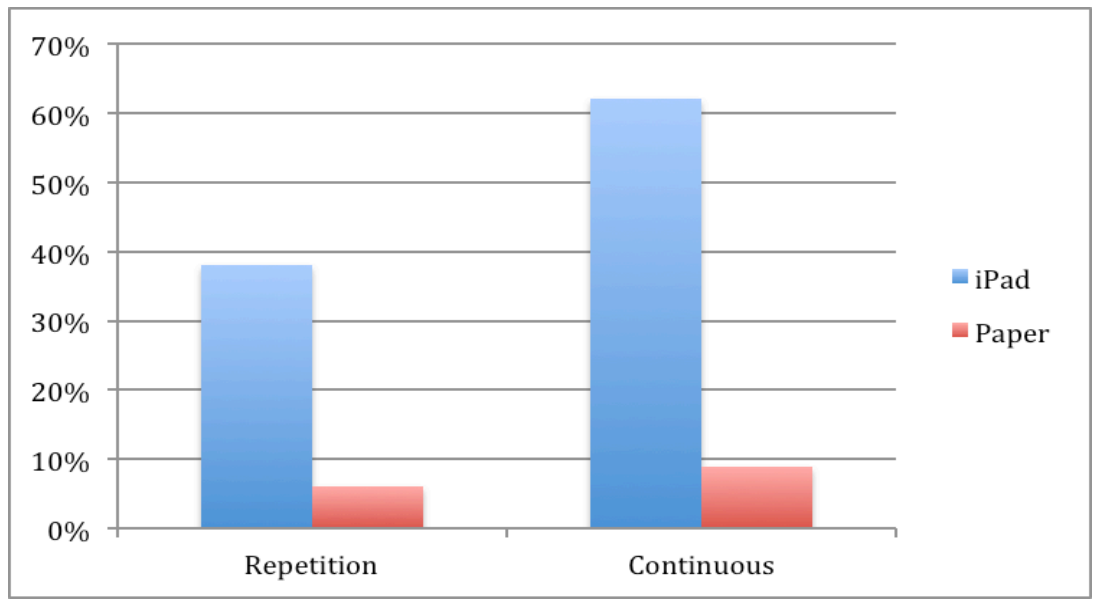

Figure 4: Distribution of touch repetition and continuous touch movements

\subsection{Qualities of Touch}

Touch varied in terms of pressure applied, scale and 'size', including dynamic changes in size i.e. getting bigger or smaller over continuous touch interactions, and faster or slower. Using a range of scale-sizes of touch, i.e. moving beyond the 'neutral' range of touches ' $1-4 \mathrm{~cm}$ ' in scale, accounted for $2 \%$ of touches made. A comparison of the scale of children's touch with the paper and the iPad suggests that this was used similarly in both environments. More than half of the children varied the scale of their touch, with large (over $4 \mathrm{~cm}$ ) touches being more common with the iPad (22 compared with 5), and tiny (finger-tip sized) touches more common with the paper (11 compared with 5). While extensive use of distinctions in the quality of touch was not apparent in this data set, these findings indicate areas for future research.

Dynamic variation in scale was rarely seen. Those children who were observed to dynamically vary the scale of their touch did so more often with the iPad: with 14 incidences of touches 'getting bigger' compared with 7 on the paper sheet.

Children used the same 'neutral' (that is neither hard nor soft) level of pressure of touch on the paper and the iPad: less than $1 \%$ of touches were observed where children noticeably varied the pressure of their touch. The use of hard pressure was observed twice as often with the iPad compared to with the paper (15 compared with 8 ). However, difficulty in visually observing the pressure of touch poses a methodological challenge, and suggests the need for different methodological processes to measure pressure.

The speed of children's touch-based interaction overall remained the same throughout most episodes of interaction with 29 observed changes in interactional speed among around half of the children. Of the children who did vary the speed, all did so with the paper and the iPad. Analysis of the video suggests however, that there were incidences of touch-based interaction that got faster with the iPad, again an aspect that requires further investigation. 

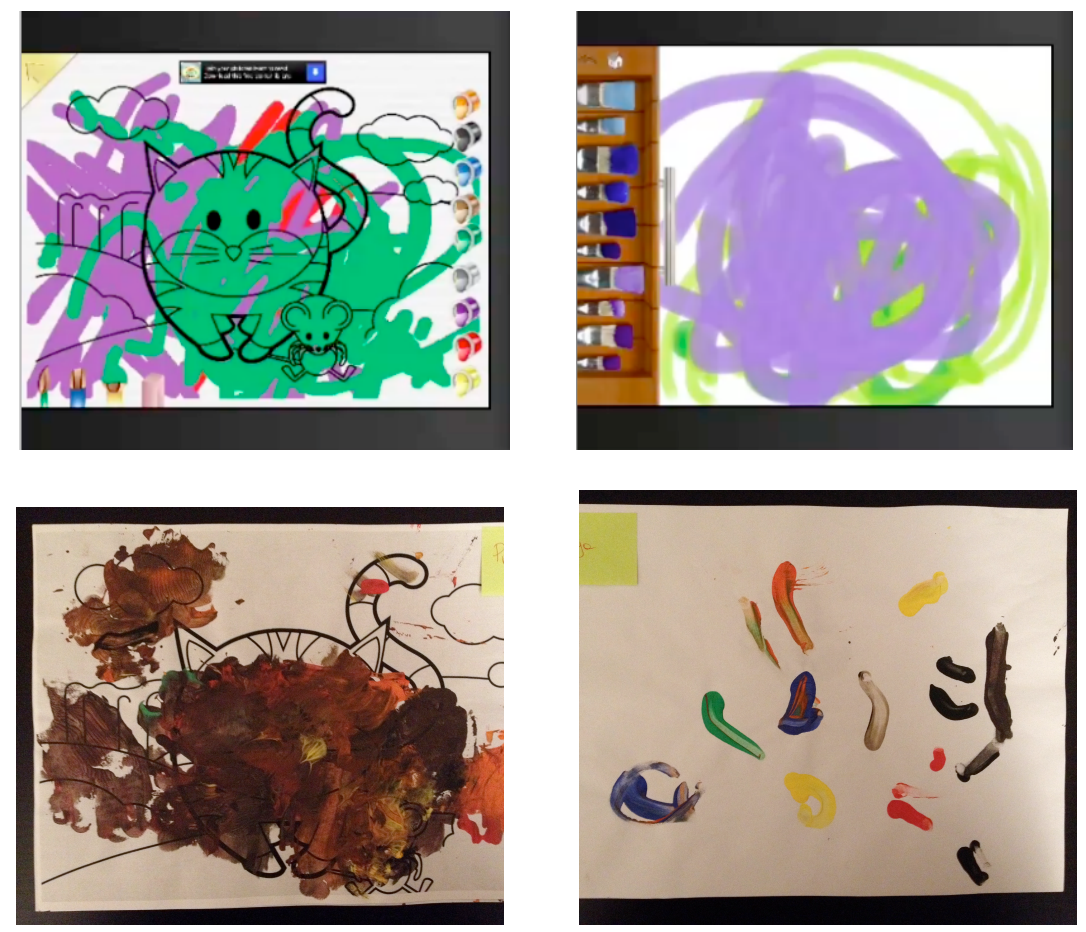

Figure 5: Example iPad cat (top left); iPad free (top right); paper cat (bottom left); free (bottom right)

\subsection{Painting Product}

All paintings were collected from each participant: two digital (cat colouring and free paint on blank screen); and two physical (cat colouring and free paint on plain paper). In the iPad activities children typically started by making marks through taps and short strokes or circles, which were then repeated and extended to overlap and overwrite existing markings, resulting in a densely coloured picture, of one or two single colours. In the paper activities touch movements were smaller, more distinct, and specific. The resulting paintings typically differed in the free painting context from the colouring in activity: the free painting maintaining smaller distinct markings, while the cat colouring comprised a denser covering of paint with overlapping layers, and consequently showed higher levels of colour mixing. On both the paper paint versions the paint texture is clearly visible, with smaller distinct lines and dots in a confined area of page, and with layers of paint on the cat colouring activity (Figure 5).

\section{Discussion}

Problematic access to children's nurseries and participants highlights the need to better understand whether and how technology is beneficial for this age group, to enable parents and educational establishments to make choices about technology based on evidence rather than assumptions. The results from this study indicate a number of interesting differences and similarities in young children's interaction with touch technologies that draw attention to how young children use iPads. Specifically differences were found in relation to finger and hand use, quantity of touch, variation of touch types, qualities of touch, and repetition and continuity of touches. Collectively this contributes to our understanding of how technology re-shapes interaction and has important implications for the use of current touch screen technologies in the home and pre-school and early years classrooms.

\subsection{Shaping Interaction and Development}


One key aspect to note is that the paint palette-paper relationship inherent in the paper environment demands interaction with two physically separate places: the paper and paint palette; and with two different materials: the paper surface and paint texture. In contrast, touch screens combine 'paper' and 'paint palette' into one surface inherently shaping interaction in particular ways in these two environments. For the purposes of this analysis both the paint palette interaction and the paper/screen interaction are included, since they both form important sites of interaction.

\subsubsection{Hand and finger use}

The results show specific differences in children's use of hands and fingers. While the index finger was most commonly used in both environments children used their palm, thumb and fingers in the paper based environment significantly more than the screen-based environment. This may not be surprising given that the use of the physical paint palette-paper more readily enables the use of the different fingers and the whole palm in 'collecting', and then distributing, paint to use on the paper. In contrast the iPad palette zone demands only a one finger touch to change the colour of the paint, not providing or encouraging other ways of transferring colour to screen, and more likely fostering index finger use.

This need to apply and reapply paint to the finger or hand serves particular functions in interaction and provides children with sensory experiences and concrete experiences of changes in physical entities that the iPad does not. It fosters a pattern of interaction that creates moments of physical 'distance' and 'removal', which offer the potential for reflection and objectification of the painting and engagement with the process (Author) (e.g. looking at the fingers, or playing with the paint on the hands, Figure 6). This form of interaction is lost in the digital, where the paint does not transfer to the finger, and neither the 'paint on the finger' nor the palette gets depleted, and has implications for the kinds of physical encounters experienced.

These interaction effects offer opportunities to experience changes in physical entities. For example, experiencing the depletion of paint from the paint palette, which eventually becomes empty; changes in proportion as the paint is redistributed (often spread) from one surface type to another; how the paint changes from one material surface to another (e.g. paper absorbs, the plastic palette does not); or experiencing properties of colour. Children often used their palm or whole hand to mix paint colours in the physical paint palette, an activity not possible in the iPad condition (in the apps used in this study). Thus the use of the palm in the palette itself serves a function that is distinctly different from the interaction affordances offered by the iPad. On the digital screen colours remain distinct as layers, completely covering any preceding colour: they do not blend on the screen as on paper, where the colours combine to create new colour combinations. Such concrete experiences provide important foundations for thinking at a conceptual level. Learning from these hands on experiences enables the development of 'schema' that facilitate conceptual development (Piaget, 1972), and fosters the discovery of connections between things (Dewey, 2001). In this context these activities contribute to children's developing understanding of material affordances and concepts of changes to physical materials.

This highlights the loss of opportunities in the iPad environment for children to experience material textures and the messiness of finger-painting (Author). However, analysis also showed that several children frequently wiped their finger or hand after placing in the paint and palette and onto the paper, and appeared to want to keep their hands clean. One child spent much of her time wiping her finger on a tissue, and when she came to do the cat colouring activity she went to get a 'stamp' to dip in the paint palette, thus avoiding the use of her hands or fingers. Future research could usefully examine cultural changes and expectations that may well be mediated by technology in children's everyday play experiences with digital versus physical sensory-based interaction. 


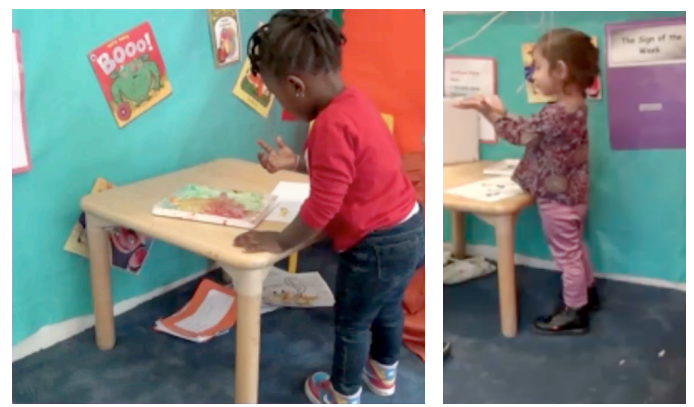

Figure 6: Children examining the physical quality of paint during the painting experience

It could be argued therefore that the restriction in terms of the quantity and range of fingers used on the touchscreen may interfere with the development of children's general and varied use of digits in early mark making, and contributes to an interaction pattern that reduces exposure to sensory experiences.

\subsubsection{Differences in touch type use}

The results show various differences in touch type use across the two environments. These findings are potentially important in understanding the role of the iPad in the development of children's writing and drawing skills, as well as digital interaction skills.

Straight strokes being more common in the iPad environment than the paint-paper environment has implications for digital interaction skills, and may specifically be a pre-requisite action for developing drag and drop techniques (Author). The action of stroking aligns closely with drag and drop actions, the key difference being that drag and drop requires awareness and skill in when to apply and release pressure. However, its high intuitive use with the iPad suggests this is a useful form of early engagement with touch screen technologies providing practice at dragging (stroking) and lifting. Applications (or new application designs) that encourage press and release at particular points in activity as well as swipe type gestures could foster such development.

Circular strokes were also used most often with the iPad. This prominent use of circular strokes as 'shapes' being formed aligns with established children's drawing and mark making strategies (Lowenfield \& Edwards, 1995). The dominant use of this movement or 'shape making' in the iPad, rather than the paper, suggests that touch screen technologies more easily afford this kind of shape making for young children, and offer a medium for developing such drawing skills. Since research suggests that children transfer these skills across media (Matthews and Seow, 2007) further research should examine how children progress to develop other shape forms on touch screens, and whether the use of fingers for this, versus writing instruments is initially beneficial.

The prominence of pressing in the paper environment suggests, perhaps unsurprisingly, that some touches are related to the sensory character of the surface. These differences point to the particular material affordances of paint and paper compared with the digital, where the children needed to physically press the paint off their fingers onto the paper, which required some level of pressure, whereas the iPad responded rapidly to a much lighter touch. Although this suggests that 'pressure skill' was intuitively picked up by the children through their interaction it may well be influenced by previous experience with the iPad.

Overall the results suggest that the iPad supports more touch-based mark making interaction than the paper in a similar period of interaction time. Specifically the iPad supported significantly more continuous touch-based interactions, and for longer durations than the paper, having a number of consequences for interaction. (i) It enables more mark making in a shorter time period. The need to return to the paint-palette in the paper condition to collect paint interrupts the flow of touch interaction, and slows down the overall painting process. As a consequence the children could make more marks and complete a 'colouring in' finger-painting task quicker in the iPad 
environment than in the paint-paper environment. (ii) It enables the linking of different types of touch into more complex sequences, leading to more variation in touch movements, and the potential to dynamically vary the size of marks being made. (iii) It enables children's touch activity to increase in speed, fostering rapid back and forth or circular movements. The frictional properties on the iPad being less than paper may contribute to this capacity to make faster strokes.

These results suggest that the iPad environment requires less time-effort, through the benefits of continuous interaction with the screen not afforded by the material qualities of the paint-paper environment. The material affordances of the iPad, therefore, support speed and continuity. The 'continuity' property is particularly interesting in the context of research that indicates that young children find screen-based swiping gestures problematic, as they tend to break their touch during the swipe motion (e.g. Brown et al., 2010). The findings here illustrate that very young children (27 months) are capable of making continuous stroke movements and continuous circular movements without releasing their finger from the screen. The relationship between the iPad environment and more varied and complex sequences of touch thus enables the development of more sophisticated touch forms of interaction. This suggests that engaging very young children in these kinds of activities may be fruitful in supporting mark making skills leading to the development of literacy and digital skills, including swipe actions.

\subsubsection{Differences in drawing outcomes}

The findings suggest that, and show how the differing nature of the painting process in the alternative environments fosters production of different compositions of paintings. The iPad, with its facility to enable continuous mark making, dynamic changes to marks etc., engendered compositions that comprised many overlapping and overwritten circles and lines, resulting in a 'more coloured in' area of the screen or painting (Figure 5). This highlights the findings that the iPad engendered more mark making. Given that stronger visual feedback increases pre-drawing behavior (Dunst \& Gorman, 2009a), the properties of the iPad with its immediate and strong visual effects may be instrumental in fostering mark making both quantitatively and qualitatively.

However, the overwriting nature of the iPad commonly resulted in a predominant colour being visible rather than the changes in visual effects that occur through the physical colour mixing properties on paper, and result in a more uniform coloured in area. In contrast the final physical paintings resulted in overall less marks on the paper, generating more individual paintings across the participants, or compositions that demonstrate the experience of colour mixing properties. This illustrates the role of physical paints in contributing to concrete experiences of properties of colour and paper material, and colour mixing.

Considering the painting pattern within each of the environments, differences are further apparent in the paper condition for the cat versus the plain screen/paper. Specifically, there is a tendency to smudge or smear paint in the physical 'colouring in' activity (i.e. the cat), and to make more distinct marks - dots or lines - in the free physical painting activity (Figure 5). The colouring in activity on paper also elicited more mark making than the plain paper. This supports earlier findings that drawing contexts with images on them (e.g. animals or faces) elicited more mark making that blank pages (Dunst \& Gorman 2009a). However, in the iPad condition the amount of mark making on the blank screen and the colouring in activity were similar, suggesting the iPad's affordance to foster more mark making in general.

\subsection{Implications for education and design}

Overall the findings suggest that the use of the iPad limits the number of fingers used for interaction, but does not limit children's mark making activity per se. In fact it extends mark making by enabling continuous marking and dynamic changes in touch types, and increases the amount of mark making. At the same time it limits the sensory experience of physical paint and results in more uniform final compositions. These findings thus indicate benefits and limitations 
of each environment, which are important in informing the role of technology in the home and early years educational contexts and technology design.

A key question is when and where it is appropriate to use digital touch screen technologies or physical materials in early years educational settings. Kennedy, Dunphy, Dwyer, Hayes, McPhillips, Marsh et al. (2010) highlight the importance of 'continuous provision' for drawing on a regular basis in fostering the development of literacy skills. The potential of iPads in this sense is high, since the practical ready-to handness of the iPad as a tool for finger based drawing/ mark making is greater than physical paint and paper - both at home and in the nursery. Furthermore, iPads offer an additional playful approach to drawing, that Anning \& Ring (2004) recommend for ensuring that both boys and girls are engaged, and thus provide more opportunities for all children to participate in important pre-requisite writing activities.

On the one hand the capacity for increased mark making with the iPad suggests it has a role to play in fostering the development of mark making towards key literacy skills. Children's ability to make continuous stroke and circular movements without releasing their finger from the screen suggests other benefits of the iPad interaction for early years. One hypothesis may be that continuous finger marking prepares the groundwork for abilities in continuous mark making with other tools, such as pen or pencil, as well as contributing to the development of forming 'shapes', and actions that underpin more sophisticated digital literacy skills. These findings also usefully inform the choice of iPad games and activities, particularly those that require continuous touch as part of an interaction experience, or that specifically require the use of different fingers or multiple touch.

On the other hand, increased mark making capacity was shown to come hand in hand with 'faster' and 'more' mark making in less time. While the findings did not suggest that the 'slower' paperbased activities engendered a capacity of engaging for longer with the mark making (since time on activity as a whole was similar in both conditions), such time-effort reduction may have negative implications for attention and concentration on the quality of mark making over time and across repeated activities with the iPads, and warrants further investigation.

Furthermore, the findings clearly highlight that the iPad lacks the range of sensory experiences enabled through physical paints. Importantly this points to organization and design of children's nursery based and home opportunities, and the use of the technology as a supplement rather than replacement for certain kinds of activities.

In terms of technology design, the results raise interesting debates and challenges. At one level they indicate the need for designing applications that encourage continuous touch-screen play activities that accommodate a wider variation in touch types, and designs that specifically foster multiple finger interaction. Indeed those that encourage multiple simultaneous use of fingers would be important in fostering the development of skills, such as swiping, where often two or more fingers are required to perform this task.

At another level the findings raise interesting challenges for system development in terms of sensory perception. Here a key question is whether technology design should rise to these challenges and aim to achieve digital skeuomorphism, i.e. be designed to mimic the physical world, or whether design should focus on creating new experiences engendered by properties of novel interfaces. If we take the latter argument then, rather than informing the design of finger painting applications per se, these findings inform ways of designing innovative games or applications (not necessarily finger painting) that build on the specific affordances of the technology to foster key skills, such as continuous touch strokes and pre-swipe based skills, which encourage additional experiences for skill development, and recognise the need for physical environments to continue to provide key material and sensory qualities of interaction. On the other hand, a skeuomorphic design, which 'simulates' or mimics the material and sensory experiences of physical paint, may well be beneficial to specific user groups e.g. physically or 
emotionally disabled, where the practicalities of working with 'messy' physical materials may be more problematic, and a digital alternative appealing, thus extending mark making opportunities for this user group.

\subsection{Future Research Directions}

These findings indicate several important future research directions. In particular potential benefits of touch-screen interaction in terms of extended touch repertoires needs to be examined to specifically understand the relationship of mark making on digital touch-screens with the development of children's skills in drawing, writing and/or typing; and examining how children progress to develop shape forms beyond circles on touch screens, and whether or how the use of fingers versus writing instruments is beneficial. This needs to be complemented by further research examining the potential of reflection inherent in the rhythmic movement demanded in the paper situation, to better understand, for example, how this 'space' influences mark making choices, and the effect on attention and concentration on the quality of mark making in comparison with iPad based mark making.

The screen-capture data collected during this study combined with the video data provides the opportunity for further research on the spatial quality of touch, i.e. exploring differences in where the children touched the paper and the iPad screen, together with the use of the digital palette, and whether this has implications for shaping the painting process and product, and extending findings reported here.

Furthermore, exploration of cultural differences in typical play experiences currently provided for children in everyday activities, would provide insight into the way that digital technology may be accepted or adopted. For example, research examining the role of 'messiness' in children's activity opportunities, may indicate whether digital technology such as this is welcomed in reducing 'messy' interaction in the home and/or nursery contexts. In conjunction, better understanding the role of adults (and even peers) in mediating children's use of touch screen technologies would provide more in depth data on the quality of the technology-based experiences. This is especially relevant given the social significance of literacy (Taylor, 1982, cited Teale and Martinez, 1987), and the essential role of adult scaffolding in emergent literacy development (Bus and Izjendoorn, 1988) and children's learning in general (Vygotsky, 1978). This would offer a better understanding of the relationship between quantity of mark-making potential, and quality of interaction, and gain insight into the effect of parental beliefs on children's motivation and engagement in mark making practice with the technology, since a high percentage of parents have been shown to believe tablets to play a valuable role in literacy development (Neumann, 2014).

\section{Conclusion}

These results indicate differential benefits and limitations of the use of iPad's (or touch screen technologies) in pre-school learning contexts, and overall seem to suggest that these technologies should be used as a complement to other activities, without lessening a prioritizing of messy, sensory experiences, such as physical painting, at this stage of child development. While the iPad environment did not engender new forms of touch movements in this age group (in the context of emulating a non-digital practice), it did engender more mark making overall with longer sequences of continuous interactions and complex linking of different touch types. These attributes suggest that the iPad facilitates important mark making activity in pre-school children, extending the kind of mark making possible with traditional physical materials, and offering a medium through which children can potentially develop important pre-requisite skills for writing and drawing. In addition, the results show how early engagement with touch screen technologies may be valuable in fostering the development of digital literacy skills, such as swiping. However, the iPad was found to restrict the use of multiple digits and hands in touch based contexts, encouraging far more index finger interaction, as well as precluding sensory tactile experiences 
enabled through paint and paper based interaction. These broader experiences continue to offer important routes to symbolic forms of understanding and expression, critical for literacy practices. Collectively these findings show how educational practitioners and parents can organize and select the use of touch screen technologies to complement traditional interactive materials, providing a wider range of experiences for young children without losing or replacing their exposure to other important activities.

\section{Acknowledgments}

TBA

\section{References}

Anthony, L., Brown, Q., Nias, J., Tate, B. \& Mohan, S. (2012). Interaction and Recognition Challenges in Interpreting Children's Touch and Gesture Input on Mobile Devices. International Conference on Interactive Tabletops and Surfaces, ACM, Cambridge, USA.

Arend, B., Sunnen, P., Fixmer, P. \& Suibert, M. (2014). Perspectives do matter - Joint Screen - a promising methodology for multimodal interaction analysis. Classroom Discourse, 5(1), 3850 .

Arrowood, D., \& Overall, T. (2004). Using technology to motivate children to write: Changing attitudes in children and preservice teachers. In R. Ferdig et al. (Eds.), Proceedings of Society for Information Technology \& Teacher Education International Conference (pp. 4985-4987).

Berk, L. (2012). Cognitive Development in Infancy and Toddlerhood. In Infants, Children and Adolescents, 202-245, Pearson.

Beschorner, B. \& Hutchison, A. (2013). iPads as a literacy teaching tool in early childhood. International Journal of Education in Mathematics, Science and Technology, 1(1), 16-24.

Blackwell, C., Lauricella, A. \& Wartella, E. (2014). Factors influencing digital technology use in early childhood education. Computers and Education, 77, 82-90.

Brown, Q., Bonsignore, E., Hatley, L., Druin, A., Walsh, G., Foss, E., Brewer, R., Hammer, J., \& Golub, E. (2010). Clear Panels: a technique to design mobile application interactivity. Designing Interactive Systems, ACM , 360-363.

Bus, A. \& Izjendoorn, M. (1988). Mother-child interactions, attachment and emergent literacy: A cross-sectional study. Child Development, 59(5), 1262-1272.

Caruthers, E. \& Worthington, M. (1988). Children's Mathematics: Making Marks, Making Meaning. $2^{\text {nd }}$ Edition, Sage.

Clark, W \& Luckin, R. (2013). What the research says - iPads in the Classroom' London Knowledge Lab. http://digitalteachingandlearning.files.wordpress.com/2013/03/ipads-in-theclassroom-report-lkl.pdf (Last retrieved December 2014).

Coates, E., \& Coates, A. (2006). Young children talking and drawing. International Journal of Early Years Education, 14, 221-241.

Couse, L. J. \& Chen, D.W. (2010). A Tablet Computer for Young Children? Exploring its viability for early childhood education. Journal of Research on Technology in Education, 43,(1), 75-98.

Dewey, J. (2001). Democracy and Education: Pennsylvania State University.

Dunst, C. \& Gorman, E. (2009b). Development of Infant and Toddler Mark Making and Scribbling. Centre for Early Learning Literacy Review. 2, No. 1.

Dunst, C. \& Gorman, E. (2009a). Development of Infant and Toddler Mark Making and Scribbling. Centre for Early Learning Literacy Review. 2, No. 2.

Goodnow, J. (1977). Children's drawing. London: Fontana/Open Books. 
Guthrie, L. F., \& Richardson, S. (1995). Language arts: Computer literacy in the primary grades. Educational Leadership, 53(2), 14-17.

Hillman, M. \& Marshall J. (2009). Evaluation of Digital Media for Emergent Literacy, Computers in the Schools. Interdisciplinary Journal of Practice, Theory, and Applied Research, 26(4), 256-270.

Indriasari Mansor, E. De Angelis, A. \& De Brujin, O. (2008). Little fingers on the tabletop: A usability evaluation in the Kindergarten. IEEE International Workshop on Horizontal Interactive Human Computer System, 93-96.

Inkpen, K.M. (2000). Drag-and-drop versus point-and-click mouse interaction styles for children. ACM ToCHI, 8, 1, 1-33.

Joiner, R., Messer, D., Light, P., \& Littleton, K. (1998). It is best to point for young children: a comparison of children's pointing and dragging. Computers in Human Behavior, 14, 3, $513-$ 529.

Kennedy, E., Dunphy, E., Dwyer, B., Hayes, G., McPhillips, T., Marsh, J., O’Connor, M., \& Shiel, G. (2012). Literacy in early childhood and primary education (Children aged 3-8 Years) (Commissioned research report, National Council of Curriculum and Assessment (NCCA)).

Kress, G. (1997). Before Writing: Rethinking the Paths to Literacy. London: Routledge.

Lowenfield, V. \& Edwards, B. (1995). Drawing development in children. http://www.learningdesign.com/Portfolio/DrawDev/kiddrawing.html\#anchor2492825 (Last retrieved Dec 2014)

LMC Academy (2013). Amazing Research Results - The Ipad And Preschool Children With Learning Challenges, Dr. Linda http://lmcacademy.com/training/amazing-research-results-theipad-and-preschool-children-with-learning-challenges/ (last retrieved, Dec 2014).

Matthews, J., \& Seow, P. (2007). Electronic paint: Understanding children's representation through their interactions with digital paint. Journal of Art Design, 26(3), 251-263.

McPake, J., Plowman, L. \& Stephen, C. (2013). Pre-school children creating and communicating with digital technologies in the home. British Journal of Educational Technology, 44, 3, 421431.

Moyles, J. (1989). Just playing? The role and status of play in early childhood education. Buckingham: Open University Press.

National Literacy Trust (2008). Boys Reading Commission Report. http://www.literacytrust.org.uk/assets/0001/4056/Boys_Commission_Report.pdf Last accessed, March 2015.

Neumann, M. (2014). An examination of touch screen tablets and emergent literacy in Australian pre-school children. Australian Journal of Education, 58(2), 109-122.

Pahl, K. (1999). Transformations: Children's Meaning Making in a Nursery. Stoke on Trent: Trentham Books.

Pegrum, M., Oakley, G. \& Faulkner, R. (2013). Schools going mobile: A study of the adoption of mobile handheld technologies in Western Australian independent schools. Australasian Journal of Educational Technology, 29(1).

Piaget, J. (1972). The Principles of Genetic Epistemology. Basic Books, New York, USA.

Ring, K. (2010). Supporting a playful approach to drawing. In P. Broadhead, J. Howard \& E. Wood (Eds.), Play and learning in the early years (pp. 113-126). London: Sage

Sulzby, E. \& Teale, W. (1991)Emergent literacy‘. In P.D. Pearson, R.Barr, M.L. Kamil, and P. Mosenthal (eds) Handbook of Reading Research, vol.2. New York: Longman. 
Strikland, D. S. (1990). Emergent Literacy: How Young Children Learn to Read and Write. Educational Leadership, 47(6), 18-23.

Teale W. \& Martinez, M. (1987). Connecting Writing: Fostering Emergent Literacy in Kindergarten Children. Centre for the Study of Reading, Technical Report 412, University of Illinois.

Vygostsky, L. (1978). The Role of Play in Development. In Mind in Society. (Trans. M. Cole). Cambridge, MA: Harvard University Press.

Whitehurst, G. \& Lonigan, C. (1998). Child Development and emergent literacy. Child Development. 69(3), 848-72. 